\title{
The Inhibition Mechanism of Surfactant Composite for Mild Steel Corrosion in NaCl Solution
}

\author{
I. Ismail ${ }^{1}$, M.K. Harun ${ }^{1 *}$ and M.Z.A. Yahya ${ }^{2}$ \\ ${ }^{I}$ Electrochemical and Corrosion Science Laboratory, Faculty of Applied Science, Universiti Teknologi MARA, 40450 \\ Shah Alam Selangor, Malaysia \\ ${ }^{2}$ Faculty of Defence Science \& Technology, Universiti Pertahanan Nasional Malaysia, 57000 Kuala Lumpur, Malaysia
}

\begin{abstract}
The corrosion inhibition of sodium deodecylbenzenesulfonate (SDBS) surfactant and $\mathrm{ZnSO}_{4}$ on mild steel in $0.05 \mathrm{M} \mathrm{NaCl}$ solution was conducted through the impedance spectroscopy and linear polarisation measurement. The inhibitors performance was measured separately and as a mixed composite of both at a ratio of 200:200 ppm. Results obtained from both these measurements indicate high corrosion inhibition of the mild steel substrates was achieved. Porosity calculation of the formed inhibition layer was done through the obtained linear polarisation data, and its dielectric properties were deduced from the impedance measurements. Two possible structures of the formed inhibitive layers are proposed. The first structure involved the formation of a stable but porous zinc oxide/hydroxide layer with the surfactant filling up the pores, thus forming a continuous inhibitive barrier film layer while the second, involved a formation of a continuous inhibitive barrier layer due to the chelation of the surfactant and $\mathrm{ZnSO}_{4}$ compounds. The results obtained also indicated that corrosion resistance induced by the inhibitive barrier layers is much more dependent on its charge transfer resistance properties rather than its dielectric properties and that the corrosion inhibition provided is not directly related to the double-layer capacitance values of the barrier layer.
\end{abstract}

Keywords: mild steel; corrosion; surfactant; $\mathrm{ZnSO}_{4}$; protective layer

\section{INTRODUCTION}

Various surface chemical pre-treatments approaches were employed to protect metals from corroding when exposed to aggressive environments. Among them are, acid pickling followed by alkaline pre-treatment, surface passivation through electro-chemically synthesized conversion coatings and the use of chemical inhibitors and/or sol-gel based surface pre-treatment (Sababi et. al., 2017; Rodrigues et al., 2013). In most cases, however, chemical inhibitors are more commonly used for mild steel structures exposed in aggressive environments (Alinejad et. al., 2017; Liu et. al., 2016; Mobin \& Khan, 2014; Umoren \& Solomon, 2017; Wang et. al., 2015; Zhou et al., 2015). There are various types of chemical inhibitors available, ranging from inorganic to organic inhibitors. Inorganic inhibitors tend to promote metal oxidation to form a passive oxide coating layer that is resistant towards corrosion attack, while organic inhibitors are usually adsorbed on the metal surfaces through heteroatoms and/or chemical bonds forming thin barrier layers (Umoren \& Solomon, 2017). The latest research trend is towards promoting the use of nontoxic, economical, and more environmentally friendly green materials as corrosion inhibitors (Mobin et al., 2017; Mobin $\&$ Khan, 2014). One approach is the use of surfactants which is known to comply with these requirements. Surfactant can contain electronegative atoms such as nitrogen , oxygen and sulfur that interact with the metal surface and thus delay corrosion reactions (Deyab, 2007). A wide number of 
surfactants are available on the market, such as anionic, cationic, non-ionic and zwitterionic surfactants (Umoren \& Solomon, 2017). An anionic surfactant, sodium dodecylbenzene sulfonate (SDBS) has been reported to be successfully used as corrosion inhibitors for metal (Sha et. al., 2019; Qiang et al., 2017). The compound contains a long nonpolar hydrocarbon chain which makes it hydrophobic. Adsorption of this hydrophobic compound on metal can prevent water from reaching the metal surface, thereby reduces the corrosion of metal. Significant inhibition performance was obtained when SDBS was used in conjunction with zinc sulphate (Ismail \& Harun, 2019), $\mathrm{Al}_{2} \mathrm{O}_{3}$ (Sha et al., 2019), cerium nitrate (Liu et al., 2016) and lanthanum chloride (Zhou et al., 2015).

In this work, sodium dodecylbenzene sulfonates (SDBS) incorporated with $\mathrm{ZnSO}_{4}$ was investigated to enhance the corrosion resistance of mild steel in $\mathrm{NaCl}$ solution. Evaluation of the protective layer barrier properties was performed using linear polarization resistance (LPR) measurements and electrochemical impedance spectroscopy (EIS) test. Based on the data obtained, the inhibition mechanism of the SDBS: $\mathrm{ZnSO}_{4}$ mixtures on mild steel were evaluated through its charge transfer resistance properties as well as its dielectric properties.

\section{MATERIALS AND METHOD}

The mild steel substrates used has a chemical composition of (wt\%) $0.60 \% \mathrm{Mn}, 0.15 \% \mathrm{C}, 0.030 \% \mathrm{P}, 0.035 \% \mathrm{~S}$ and 99.185\% Fe. Its surface abraded with emery papers (500, $800,1200,2400$ grit sizes) before used. The sample was cleaned twice with deionized water and acetone before leaving it to dry. Analytical grades of sodium dodecylbenzenesulfonates (SDBS) was obtained from Aldrich, while zinc sulfate $\left(\mathrm{ZnSO}_{4}\right)$ was supplied by $\mathrm{HmBG}$ chemicals, and used as received. The inhibitor solutions were prepared by dissolving each of the SDBS and $\mathrm{ZnSO}_{4}$ in $0.05 \mathrm{M} \mathrm{NaCl}$ solution and stirred for 15 minutes. The concentrations of SDBS used for the study is $200 \mathrm{ppm}$, and $200 \mathrm{ppm}$ for $\mathrm{ZnSO}_{4}$. Then, a mix solution of $200 \mathrm{ppm}: 200$ ppm of both SDBS and $\mathrm{ZnSO}_{4}$ was prepared. This was done by first dissolving SDBS in sodium chloride solution, followed by $\mathrm{ZnSO}_{4}$ and was stirred for 15 minutes. Deionized water was used to prepare all the solutions.

\section{A. Electrochemical measurement}

A conventional three-electrode cell of $\mathrm{Ag} / \mathrm{AgCl}$ reference electrode coupled to a Luggin capillary, a platinum counter electrode, and a mild steel sample as a working electrode were used. The working electrode was prepared by embedding a $1 \mathrm{~cm}^{2}$ mild steel sample into epoxy resin, leaving an exposed area of $0.054 \mathrm{~cm}^{2}$. The test solution used was $0.05 \mathrm{M} \mathrm{NaCl}$ consisting of $\mathrm{ZnSO}_{4}$, SDBS and a mixture of both compounds. All measurements were taken at $25^{\circ} \mathrm{C}$ after one hour of immersion in the test solution. The electrochemical impedance spectroscopy (EIS) was carried out at the open circuit potential (OCP) within the frequency range of $10 \mathrm{kHz}-20 \mathrm{mHz}$ with $\mathrm{AC}$ signals of amplitude 10 $\mathrm{mV}$ peak to peak. Meanwhile, the polarization measurement was conducted in a range from $-100 \mathrm{mV}$ to $+100 \mathrm{mV}$ vs. OCP with a scan rate of $1 \mathrm{mV} / \mathrm{s}$. All electrochemical experiments were conducted using the Autolab potentiostat/galvanostat model PGstat302N. The data were analyzed using the Nova software version 1.11 .

\section{RESULT AND DISCUSSION}

Figure 1 illustrates the Nyquist and Bode diagrams obtained from the impedance measurements. The Nyquist plot obtained, could measure the charge transfer resistance and double-layer capacitance exhibits a single depressed semicircle when moving from high to low frequencies (Qian et. al., 2013; Tian et al., 2018). The spectra clearly show a larger diameter of the semicircle for samples immersed in a sodium chloride solution containing each of the two inhibitors when compared to the blank solution. However, when these two inhibitors were mixed, the diameter of the semicircle was significantly increased. There was a significant increase in the total impedance value of the charge transfer processes and thus a more effective corrosion inhibition. The high impedance effect of the inhibitors is seen through the high total impedance values obtained at the low frequency of the Bode plot. The subsequent increase in the phase angle value that shifted towards a higher frequency, further confirms an increase in the total corrosion resistant of the mild steel. 

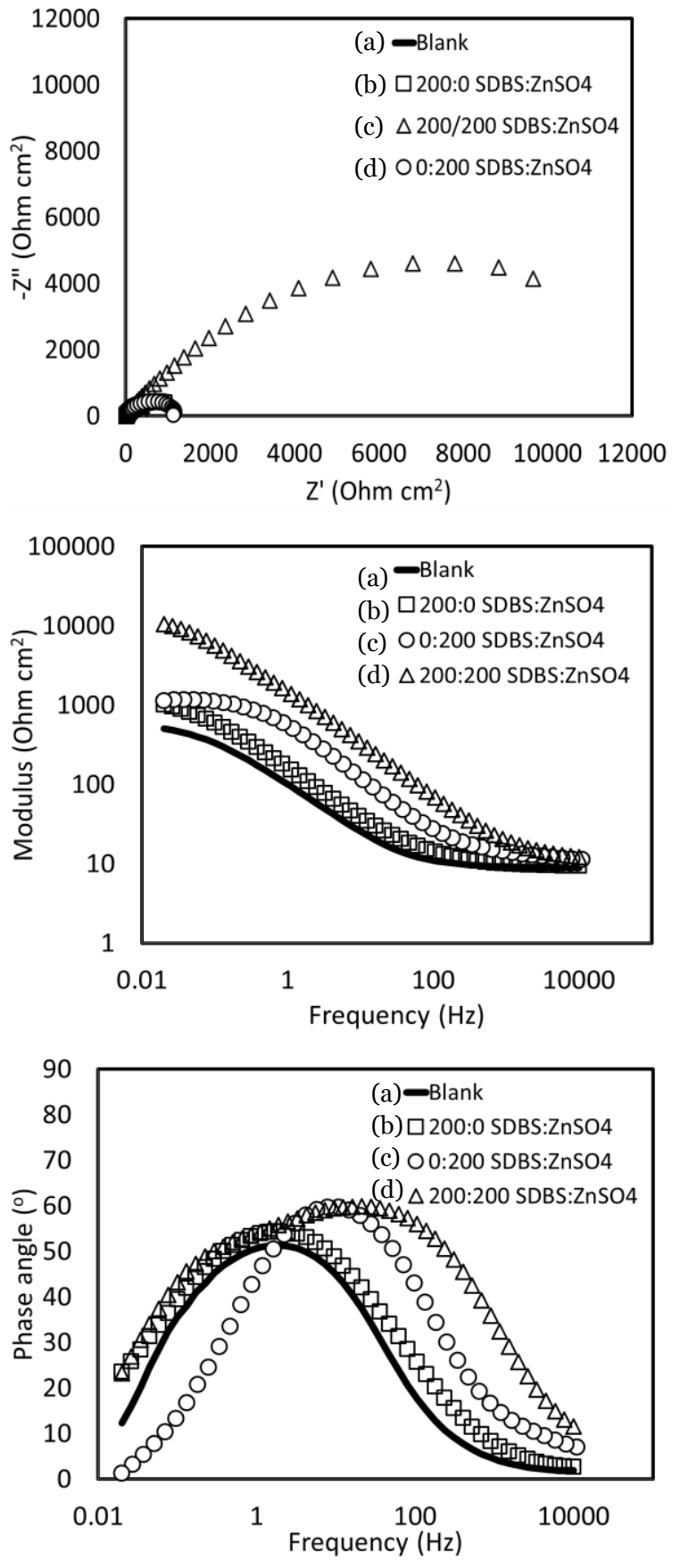

Figure 1. Typical impedance spectra of bare mild steel after immersion for $1 \mathrm{~h}$ in $0.05 \mathrm{M} \mathrm{NaCl}$ (a) without inhibitor (Blank), ( b) with 200:0 ppm SDBS: $\mathrm{ZnSO}_{4}$ (c) with 0:200 ppm SDBS:ZnSO ${ }_{4}$ (d) with 200:200 ppm SDBS:ZnSO

An equivalent electrical circuit (EEC) is used to fit the experimental data obtained. This is shown in Figure 2. The circuit comprises of $\mathrm{R}_{\mathrm{s}}$, solution resistance, $\mathrm{R}_{\mathrm{ct}}$, charge transfer resistance, and $C_{d l}$, double-layer capacitance. Due to the non-ideal capacitive behaviour, a constant phase element (CPE) was introduced instead of using a pure capacitor (Qian, 2013; Ismail et al., 2015). The result was shown in Table 1. Data fit the EEC revealed higher $\mathrm{R}_{\mathrm{ct}}$ values obtained for mild steel immersed in $\mathrm{NaCl}$ solution containing either SDBS or $\mathrm{ZnSO}_{4}$ when compared to blank. This confirms that both compounds are able to resist corrosion of mild steel. Although the compounds can each act to resist corrosion individually, however, their combination was found to be more effective. The inhibition efficiency of 96\% was obtained at a ratio of 200:200 ppm SDBS: $\mathrm{ZnSO}_{4}$. According to Alinejad, this phenomenon is associated with the formation of a good protective coating layer of complex molecules that prevents the electrolyte from diffusing towards the mild steel surface (Alinejad et al., 2017). A significant decrease in $\mathrm{Cdl}$ values was also obtained from $175 \mu \mathrm{F}$ for the blank to $15 \mu \mathrm{F}$ when both SDBS and $\mathrm{ZnSO}_{4}$ were added. It was speculated that this is due to both the displacement of the water molecules on the mild steel surface by both the zinc cations and SDBS mixture and the presence of $\mathrm{Zn}^{2+}$ and $\mathrm{SO}_{4}{ }^{2-}$ ions within the protective layer which contributed to the lower total dielectric values (Rao et al., 2011).

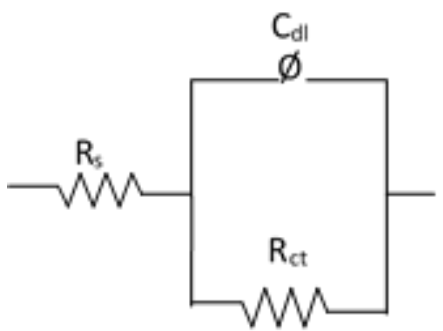

Figure 2. An equivalent electrical circuit used to fit the experimental data

Table 1. EIS measurement of the effects of SDBS and $\mathrm{ZnSO}_{4}$ on steel surfaces after immersion for $1 \mathrm{~h}$ in $0.05 \mathrm{M} \mathrm{NaCl}$

\begin{tabular}{ccccc}
\hline \multicolumn{2}{c}{$\begin{array}{c}\text { Concentration } \\
(\mathbf{p p m})\end{array}$} & $\begin{array}{c}\mathbf{R}_{\mathbf{c t}} \\
(\mathbf{O h m} \\
\left.\mathbf{c m}^{2}\right)\end{array}$ & $\begin{array}{c}\mathbf{C}_{\text {dl }} \\
(\boldsymbol{\mu F})\end{array}$ & $\begin{array}{c}\eta_{\text {EIS }} \\
(\%)\end{array}$ \\
\hline 0 & 0 & 603 & 175 & - \\
200 & 0 & 1414 & 140 & 57 \\
0 & 200 & 1246 & 14 & 52 \\
200 & 200 & 14688 & 15 & 96 \\
\hline
\end{tabular}

Polarisation measurements of the pre-treated samples were also obtained. As evidenced by the data obtained, the mixture of 200:200 ppm $\mathrm{ZnSO}_{4}$ : SDBS gives the smallest 
$\mathrm{i}_{\text {corr }}$ value, indicating a high corrosion resistance provided by the formed protective layer,(Ismail et al., 2019). The slight shift to a less negative value of the $\mathrm{E}_{\text {corr }}$ when compared to the blank shows the mixture inhibitors provided an anodic inhibition effect on the corrosion reaction. In addition to these values, the percentage porosity of the protective layer was also determined through the use of equation 1 (Creuz et al., 2000; Chaudhari \& Patil, 2010)

$$
P=\frac{R_{p o}}{R_{p i}} \times 10^{-\left(\left|\Delta E_{c o r r}\right| / \beta_{a}\right)}
$$

Where $\mathrm{P}$ is the total porosity, $\Delta \mathrm{E}_{\text {corr }}$ is the difference between corrosion potentials, $\mathrm{R}_{\mathrm{po}}$ and $\mathrm{R}_{\mathrm{pi}}$ are the polarization resistances for the blank and with inhibitors respectively. $\quad \beta_{a}$ is the anodic Tafel slope for the blank sample.

Table 2 shows the percentage porosity of the protective layer, which was at its smallest value when a ratio of 200:200 SDBS : $\mathrm{ZnSO}_{4}$ which contributed further to the total high resistance towards corrosion of the mild steel. Figure 3 and Table 3 show a less negative potential difference value $(\varphi)$ of the surface of the mild steel in the presence of $\mathrm{ZnSO}_{4}$ when compared to the blank solution. This phenomenon is related to the zero charge potential of the surface after the adsorption of $\mathrm{ZnSO}_{4}$ on the mild steel surface. It was speculated less negative potential effect of the $\mathrm{ZnSO}_{4}$ on the mild steel surface tends to promote the adsorption of SDBS compound. The electrostatic adsorption between SDBS and $\mathrm{Al}_{2} \mathrm{O}_{3}$ also was described by Sha et al. in which promotes the formation of a more compact protective layer on the brass surface (Sha et al., 2019).

Table 2. Influence of the SDBS and $\mathrm{ZnSO}_{4}$ on the polarization measurements of mild steel after immersion for $1 \mathrm{~h}$ in $0.05 \mathrm{M} \mathrm{NaCl}$

\begin{tabular}{llllll}
\hline $\begin{array}{l}\text { Concentration } \\
(\mathrm{ppm})\end{array}$ & $\boldsymbol{\beta}_{\mathrm{a}}$ & $\boldsymbol{\beta}_{\mathrm{c}}$ & $\mathbf{E}_{\text {corr }}$ & $\mathbf{i c}_{\mathrm{c}}$ & $\mathrm{P}$ \\
& $(\mathrm{mV} /$ & $\mathrm{mV} /$ & $(\mathrm{V})$ & $(\boldsymbol{\mu A} /$ & $(\%)$ \\
& $\mathrm{dec})$ & $\mathrm{dec})$ & & $\left.\mathrm{cm}^{2}\right)$ &
\end{tabular}

\begin{tabular}{ccccccc}
\hline $\begin{array}{c}\mathrm{SDB} \\
\mathrm{S}\end{array}$ & $\mathrm{ZnSO}_{4}$ & & & & & \\
$\mathrm{O}$ & 0 & 110 & 219 & -0.532 & 21.42 & - \\
200 & 0 & 90 & 118 & -0.458 & 10.76 & 72 \\
0 & 200 & 58 & 178 & -0.619 & 10.20 & 80 \\
200 & 200 & 72 & 89 & -0.476 & 1.07 & 9 \\
\hline
\end{tabular}

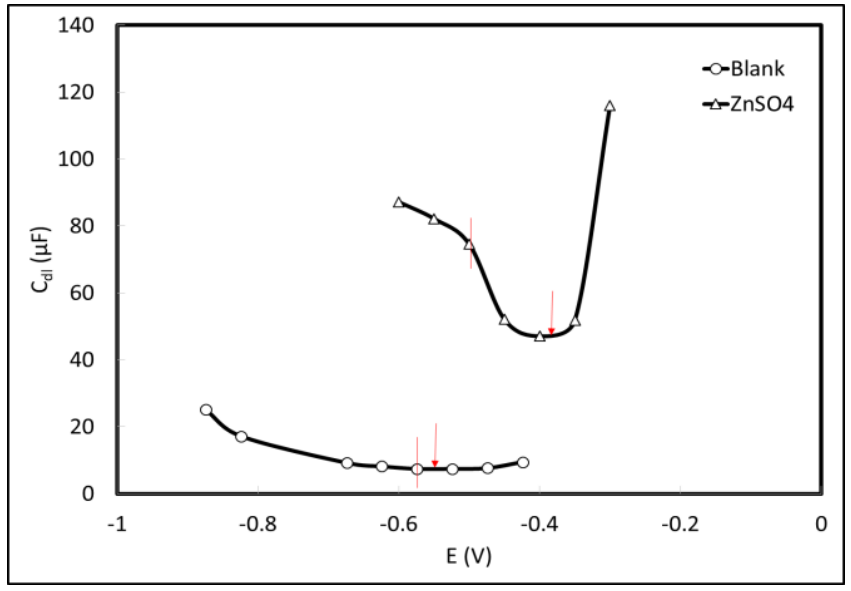

Figure 3. Variation of capacitance, $\mathrm{Cdl}$ of mild steel with potential measured in $0.05 \mathrm{M} \mathrm{NaCl}$

Table 3. Values of $\mathrm{E}_{\mathrm{cor}}, \mathrm{E}_{\mathrm{pzc}}$ and $\phi$ for mild steel in $0.05 \mathrm{M}$ $\mathrm{NaCl}$

\begin{tabular}{lccc}
\hline Solution & $\begin{array}{c}\mathbf{E}_{\mathbf{c o r}} \\
(\mathbf{V})\end{array}$ & $\begin{array}{c}\mathbf{E}_{\mathbf{p z c}} \\
(\mathbf{V})\end{array}$ & $\boldsymbol{\varphi ( V )}$ \\
\hline $0.05 \mathrm{M} \mathrm{NaCl}$ & -0.500 & -0.38 & -0.12 \\
$0.05 \mathrm{M} \mathrm{NaCl}+200$ & -0.574 & -0.499 & -0.075 \\
ppm $\mathrm{ZnSO} 4$ & & & \\
\hline
\end{tabular}

There are two possible structures of the $\mathrm{ZnSO}_{4}$ :SDBS mixture protective layer proposed, on the mild steel that accounts the porosity and capacitance values obtained from the experiments. The first structure is in the form of the formation of a stable but porous zinc oxide/hydroxide layer with the SDBS filling up the pores that block the porosity as illustrated in Figure 4(a). In this case, zinc oxide/hydroxide layer blocks the oxidation reaction of mild steel, while SDBS clogged the coating pores, resulting in the higher $R_{c t}$ value and higher corrosion resistance. At the same time, the value of $\mathrm{C}_{\mathrm{dl}}$ is decreased caused by the low dielectric values of zinc oxide/hydroxide that then increases the ionic properties of the layer. Therefore it allows the transfer of charges during the measurement, consequently reduces the $\mathrm{C}_{\mathrm{dl}}$ values.

The second possible structure proposed involves the chelation of SDBS and $\mathrm{ZnSO}_{4}$ compounds. In this case, zinc oxide/hydroxide are suspended in the SDBS layer, which blocks the oxidation of iron on the surface, consequently, reduces the cathodic reaction, Figure 4(b). Both these structural models proposed, would result in an increase of the $R_{c t}$ value and a decreased $C_{d l}$ values of the protective layer as obtained in EIS measurement results. 
This result is consistent with the finding by Sha et al. who reported that SDBS can be adsorbed faster onto the brass surface when both SDBS and $\mathrm{Al}_{2} \mathrm{O}_{3}$ nanoparticles co-exist in which forming a better protective layer (Sha et al., 2019). This is attributed to the electrostatic adsorption between $\mathrm{Al}_{2} \mathrm{O}_{3}$ nanoparticles and SDBS and the increase in the CMC of SDBS caused by $\mathrm{Al}_{2} \mathrm{O}_{3}$. Both of these factors promote the formation of a more compact protective layer on the brass surface.
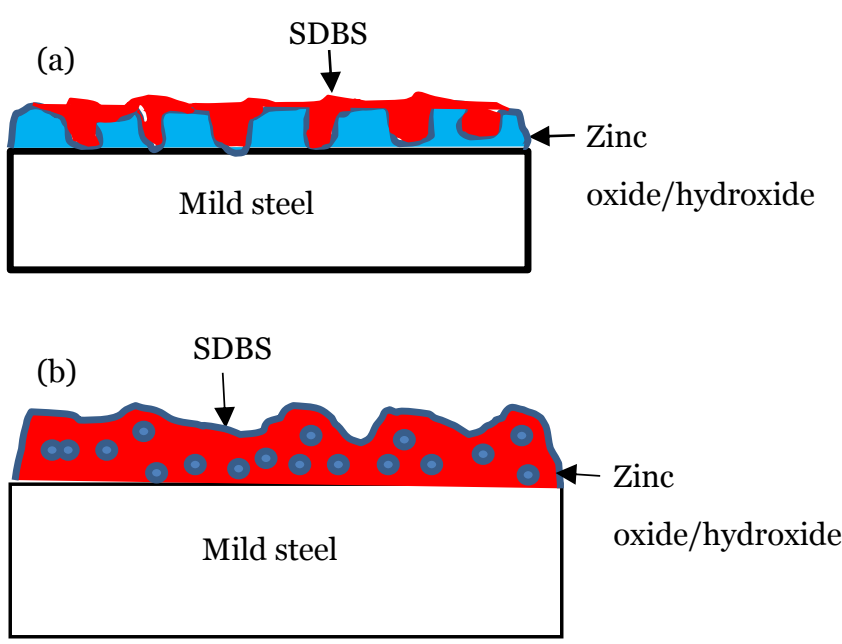

Figure 4. Formation of corrosion protection layers on mild steel surface in $\mathrm{NaCl}$ solution containing 200:200 ppm $\mathrm{ZnSO}_{4}$ :SDBS mixtures

It has often been regarded that good pre-treatment barrier protection is associated with a barrier layer that could provide high-charge transfer resistant. This property is critical for corrosion barrier protection layer as it means that it could impede the charge flow through it and thus forms an effective insulative layer to prevent metal from corroding. However, the charge flow will occur if water can diffuse through the barrier layer, thus providing pathways to facilitate charge transfer processes (Alinejad et al., 2017). A barrier layer that absorbs water through diffusion would eventually exhibit a higher double-layer capacitance value at high frequency, due to the higher dielectric constant of water. This experiment was observed that pre-treating the mild steel individually with SDBS or $\mathrm{ZnSO}_{4}$ contributes to an almost equal charge transfer resistance values, thus giving almost the same inhibition efficiency. Consequently, SDBS exhibits a higher $\mathrm{C}_{\mathrm{dl}}$ value compared to $\mathrm{ZnSO}_{4}$ which may indicate the higher concentration of water in the layer as compared to $\mathrm{ZnSO}_{4}$ layer (Table 1). It was seen here that pre-treatment with SDBS alone gives a higher $\mathrm{C}_{\mathrm{dl}}$ value than that of $\mathrm{ZnSO}_{4}$, while the $\mathrm{R}_{\mathrm{ct}}$ for both systems were about the same, hence proving an almost equal corrosion inhibition efficiency by both pre-treatment. This is further supported by the results on corrosion current $i_{\text {corr, }}$ obtained through the polarisation resistance measurements, which indicated an almost equal values (Table 2) for both systems. On the other hand, when a mixture of equal proportion of SDBS and $\mathrm{ZnSO}_{4}$ was made as to the pre-treatment layer, a much higher $R_{c t}$ value was obtained and consequently a high inhibition efficiency, with an almost equal value of $\mathrm{C}_{\mathrm{dl}}$ when compared to $\mathrm{ZnSO}_{4}$ pre-treatment alone. Combining both as a mixture as pre-treatment provided a much higher charge transfer resistance value and corrosion resistance. It was also observed, that the mixture of both compounds at the ratio of 200:200 ppm was able to produce a barrier layer of low double-layer capacitance value at high frequency, indicating no water absorption through diffusion happened throughout the experiment. Thus, the experiment shows that different barrier protection layers that possess different dielectric properties may result in the same corrosion protection ability. In this case, corrosion inhibition of the barrier layers is much more dependent on its $R_{c t}$ properties than its dielectric properties. Corrosion inhibition is not directly reliant on $\mathrm{Cdl}$ values of the barrier layer.

\section{CONCLUSION}

In this paper, the corrosion behaviour of mild steel in $\mathrm{NaCl}$ solution was investigated by electrochemical measurements. The charge transfer resistance $R_{c t}$ of the mild steel increased, and the capacitance values $\mathrm{C}_{\mathrm{dl}}$ decreased correspondingly to the formation of insoluble zinc hydroxide/oxide protective layer together with the SDBS compound on the mild steel surface. The mild steel exhibited high corrosion resistance due to the maximum impedance and minimum corrosion current density of the mild steel in $\mathrm{NaCl}$ solution. In this case, the barrier layer's corrosion inhibition is not directly reliant on its $\mathrm{C}_{\mathrm{dl}}$ values but rather on its charge transfer resistance properties of the barrier layer. 
Two inhibition mechanisms were proposed. The first mechanism is the mild steel surface was mainly covered by a porous zinc hydroxide/oxide layer. SDBS clogged the pores and blocks the porosity of the layer resulting in high impedance value. The second mechanism is due to the chelation between SDBS and $\mathrm{ZnSO}_{4}$, that contributes to higher barrier properties.

\section{ACKNOWLEDGEMENT}

The authors would like to thank the Faculty of Applied Sciences, Universiti Teknologi MARA, for permitting to

\section{REFERENCES}

Alinejad, S, Naderi, R, \& Mahdavian, M 2017, 'Effect of inhibition synergism of zinc chloride and 2mercaptobenzoxzole on protective performance of an ecofriendly silane coating on mild steel', Journal of Industrial and Engineering Chemistry, vol. 48, pp. 88-98.

Creus, J, Mazille, H, \& Idrissi, H 2000, 'Porosity evaluation of protective coatings onto steel, through electrochemical techniques', Surface and Coatings Technology, vol. 130, no. 2-3, pp. 224-232.

Chaudhari, S \& Patil, PP 2010,'Inhibition of steel corrosion by electrosynthesized poly(o-anisidine)dodecylbenzenesulfonate coatings', Electrochimica Acta, vol. 55, no. 22, pp. 6715-6723.

Deyab, M 2007, 'Effect of cationic surfactant and inorganic anions on the electrochemical behavior of carbon steel in formation water', Corrosion Science, vol. 49, pp. 23152328.

Ismail, I, Harun, MK, \& Yahya, MZA 2019, 'Corrosion protection of mild steel by the synergetic effect of sodium dodecylbenzenesulfonates and zinc sulfate in sodium chloride solution', International Journal of Electrochemical Sciences, vol. 14, pp. 11491-11508.

Ismail, I, Harun, MK, \& Yahya, MZA 2015, 'Effects of dissolved oxygen on the integrity of industrial chlorinated rubber-based primer used in rubber/metal composites', Rubber Chemistry and Technology, vol. 88, no. 3, pp. 502514

Liu, J, Wang, D, Gao, L, \& Zhang, D 2016, 'Synergism between cerium nitrate and sodium dodecylbenzenesulfonate on corrosion of AA5052 publish this paper and the Malaysian Rubber Board for their technical support of the tasks. Lastly, immense gratitude to the Fundamental Research Grant Scheme, Malaysian Ministry of Education with Grant Number 60o-IRMI/FRGS $5 / 3$ (o37/2019) for funding this research work. aluminium alloy in 3 wt.\% $\mathrm{NaCl}$ solution', Applied Surface Science, vol. 389, pp. 369-377.

Mobin, M \& Khan, MA 2014, 'Adsorption and corrosion inhibition behavior of polyethylene glycol and surfactants additives on mild steel in $\mathrm{H}_{2} \mathrm{SO}_{4}$, Journal of Materials Engineering and Performance, vol. 23, no. 1, pp. 222-229.

Mobin, M, Parveen, M, \& Rafiquee, M 2017, 'Synergistic effect of sodium dodecyl sulfate and cetyltrimethyl ammonium bromide on the corrosion inhibition behavior of l-methionine on mild steel in acidic medium', Arabian Journal of Chemistry, vol. 10, pp. S1364-S1372.

Qian, B, Hou, B, \& Zheng, M 2013, 'The inhibition effect of tannic acid on mild steel corrosion in seawater wet/dry cyclic conditions', Corrosion Science, vol. 72, pp. 1-9.

Qiang, Y, Zhang, S, Guo, L, Xu, S, Feng, L, Obot, IB \& Chen, S 2017, 'Sodium dodecyl benzene sulfonate as a sustainable inhibitor for zinc corrosion in $26 \% \mathrm{NH} 4 \mathrm{Cl}$ solution', Journal of Cleaner Production, vol. 152, pp. 1725 .

Rao, BA, Rao, MV, Rao, SS, \& Sreedhar, B 2011, 'Synergistic effect of N, N-bis (phosphonomethyl) glycine and zinc ions in corrosion control of carbon steel in cooling water systems', Chemical Engineering Communications, vol. 198, no. 12, pp. $1505-1529$.

Rodrigues, DD, \& Broughton, JG 2013, 'Silane surface modification of boron carbide in epoxy composites', International Journal of Adhesion and Adhesives, vol. 46, pp. 62-73.

Sababi, M, Terryn, H, \& Mol, JMC 2017, 'The influence of a $\mathrm{Zr}$-based conversion treatment on interfacial bonding 
strength and stability of epoxy coated carbon steel', Progress in Organic Coatings, vol. 105, pp. 29-36.

Sha,JY, Ge, HH, Wan, C, Wang, LT, Xie, SY, Meng, XJ, \& Zhao, YZ 2019, 'Corrosion inhibition behaviour of sodium dodecyl benzene sulphonate for brass in an $\mathrm{Al}_{2} \mathrm{O}_{3}$ nanofluid and simulated cooling water', Corrosion Science, vol. 148, pp. 123-133.

Tian, H, Li, W, Liu, A, Gao, X, Han, P, Ding, R, Yang, C, \& Wang, D 2018, 'Controlled delivery of multi-substituted triazole by metal-organic framework for efficient inhibition of mild steel corrosion in neutral chloride solution', Corrosion Science, vol. 131, pp. 1-16.

Umoren, SA \& Solomon, MM 2017, 'Synergistic corrosion inhibition effect of metal cations and mixtures of organic compounds: a review', Journal of Environmental Chemical Engineering, vol. 5, no. 1, pp. 246-273.

Wang, D, Yang, D, Zhang, D, Li, K, Gao, L, \& Lin, T 2015, 'Electrochemical and DFT studies of quinoline derivatives on corrosion inhibition of AA5052 aluminium alloy in $\mathrm{NaCl}$ solution', Applied Surface Science, vol. 357, Part B, pp. 2176-2183.

Zhou, B, Wang, Y, \& Zuo, Y 2015, 'Evolution of the corrosion process of AA 2024-T3 in an alkaline $\mathrm{NaCl}$ solution with sodium dodecylbenzenesulfonate and lanthanum chloride inhibitors', Applied Surface Science, vol. 357, Part A, pp. 735-744. 